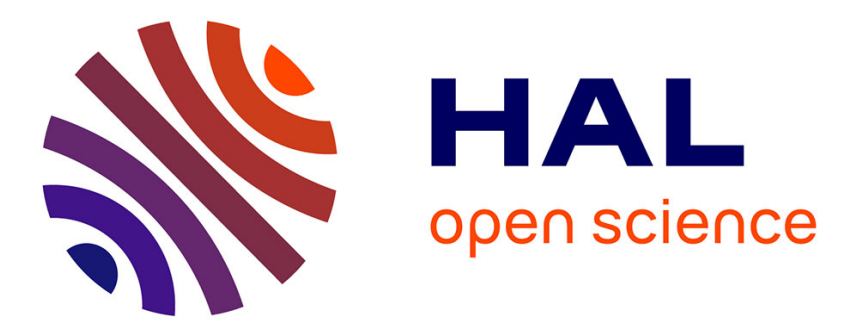

\title{
Prevalence of pilus-encoding islets and clonality of pneumococcal isolates from children with acute otitis media
}

\author{
A. Vainio, T. Kaijalainen, A. J. Hakanen, A. Virolainen
}

\section{To cite this version:}

A. Vainio, T. Kaijalainen, A. J. Hakanen, A. Virolainen. Prevalence of pilus-encoding islets and clonality of pneumococcal isolates from children with acute otitis media. European Journal of Clinical Microbiology and Infectious Diseases, 2011, 30 (4), pp.515-519. 10.1007/s10096-010-1112-y . hal00668579

\author{
HAL Id: hal-00668579 \\ https://hal.science/hal-00668579
}

Submitted on 10 Feb 2012

HAL is a multi-disciplinary open access archive for the deposit and dissemination of scientific research documents, whether they are published or not. The documents may come from teaching and research institutions in France or abroad, or from public or private research centers.
L'archive ouverte pluridisciplinaire HAL, est destinée au dépôt et à la diffusion de documents scientifiques de niveau recherche, publiés ou non, émanant des établissements d'enseignement et de recherche français ou étrangers, des laboratoires publics ou privés. 
1 Prevalence of pilus-encoding islets and clonality of pneumococcal isolates from

2 children with acute otitis media

3

4

5

6

7

8

9 National Institute for Health and Welfare (THL), Helsinki, Finland

10 (2) Department of Vaccination and Immune Protection, National Institute for Health and

11 Welfare (THL), Oulu, Finland

12 (3) Department of Infectious Disease Surveillance and Control,

13 National Institute for Health and Welfare (THL), Turku, Finland

14

15 Corresponding author

16 Anni Vainio

17 National Institute for Health and Welfare

18 P.O. Box 30, 00271 Helsinki, Finland

19 Phone: +358-20-6108171

20 Fax: +358-20-6108238

21 E-mail: anni.vainio@ thl.fi 


\section{Abstract}

25 We characterized prevalence of pilus islets 1 (PI-1) and 2 (PI-2) and clonality of

26 Streptococcus pneumoniae isolates taken from children with acute otitis media (AOM) to

27 study the association between pilus existence and AOM disease potential prior to

28 pneumococcal conjugate vaccine and increased antimicrobial resistance.

29 The study material consisted of 75 pneumococcal isolates cultured from middle ear fluid

30 and/or nasopharyngeal aspirate of 56 children with AOM in Finland during 1990-1992.

31 Isolates were studied for antimicrobial susceptibility and were serotyped, genotyped by

32 multilocus sequence typing (MLST), and tested for the presence of pneumococcal PI-1

33 and PI-2 genes.

34 All isolates were susceptible to penicillin, 14 different serotypes were found, and $20 \%$ of

35 the isolates were positive for PI-1 genes. PI-2 genes were not found. MLST showed high

36 heterogeneity: 52 AOM isolates belonged to 18 known Clonal Complexes (CC). PI-1 was

37 associated with serotypes 6A, 6B, and 9V, and genotype CC490.

38 In the time prior to PCV7 and increased antimicrobial resistance, pneumococcal AOM

39 isolates carried PI-1 genes in rather low prevalence. PI-2 genes were not detected. PI-1

40 was related with serotype rather than genotype. The importance of PI-1 in AOM

41 infections and its association with the spread of antimicrobial resistance requires further 42 research. 


\section{$43 \quad$ Keywords}

44 Streptococcus pneumoniae; acute otitis media; pilus; MLST; clonal complex;

45 antimicrobial resistance

\section{Introduction}

47 Acute otitis media (AOM) is one of the most common infectious diseases among young

48 children in developed countries. Streptococcus pneumoniae is still a major bacterial

49 pathogen causing AOM infections. Although the 7-valent pneumococcal conjugate

50 vaccine (PCV7) has been reported as decreasing the number of pneumococcal AOM

51 episodes [1], an increasing trend of AOM incidences caused by non-PCV7 serotypes of $S$.

52 pneumoniae have been observed between 2007 and 2009 in the U.S.A. [2].

53 Pneumococci have been shown to contain pilus structures encoded by pilus islets 1 (PI-1)

54 and 2 (PI-2) [3, 4]. The presence of these pilus islets in some clinical isolates seems to

55 vary in terms of serotypes and genotypes, with claims that antimicrobial-resistant clones

56 are more likely to carry the pilus islet than sensitive ones, while it has been reported that

57 PI-1 correlates with the $S$. pneumoniae genotype rather than serotype [5-9]. PI-1 has been

58 shown to play a role in adherence and virulence in murine models of pneumococcal

59 infection [4] and PI-2 pilus plays a role in adhesion to human respiratory cells in-vitro [3].

60 However, no such evidence on virulence has yet been reported for human infections.

61 In order to elucidate the pilus association with the disease potential of S. pneumoniae in

62 AOM infections we characterized the clonality and the PI-1 and PI-2 prevalence in

63 pneumococci isolated from the middle ear fluid (MEF) and/or nasopharyngeal aspirate

64 (NPA) of children with AOM in Finland. These isolates were obtained already in 1990-

65 1992, prior to PCV-7 and increased antimicrobial resistance [10]. 


\section{Materials and methods}

67 Between 1990 and 1992, 106 children were examined and treated for AOM as outpatients

68 at the Department of Otolaryngology of the Helsinki University Central Hospital. The

69 bacteria isolated from samples of middle ear fluids (MEF) and nasopharyngeal aspirates

70 (NPA) taken at the initial visit were identified by standard methods [11].

71 All pneumococcal isolates were subjected to antimicrobial susceptibility testing,

72 pneumococcal serotyping, and PCR detection for the presence of PI-1 genes $(r \operatorname{lrA}, r r g C)$

73 and PI-2 genes (pitA-sipA) [3, 6, 12, 13].

74 Multilocus sequence typing (MLST) was performed as described previously [13]. The

75 sequencing results were compared against the MLST database and the sequence types

76 (STs) assigned. The clonal complex (CC) for each ST was determined by eBURST V3

77 analysis, using default stringent parameters. In this study, the CCs were named according

78 to the highest number of single-locus variants found for the ST in November 2009.

79 Statistical analysis was done with the free GraphPad software. For categorical data,

80 proportions were compared by Fisher's exact test. $P$ values $<0.05$ were considered

81 statistically significant.

\section{Results}

84 Among the 106 children with clinically defined AOM, 56 children (median age 33

85 months, age range from 9 months to 83 months) were found to be $S$. pneumoniae culture

86 positive and were divided into three groups on the basis of the pneumococcal culture in

87 the MEF and/or NPA: 1) MEF and NPA culture positive for $S$. pneumoniae

88 [pneumococcal (Pnc) carriers with Pnc AOM, N=19, median age 24 months]; 2) MEF 
89 culture positive but NPA negative for $S$. pneumoniae [Pnc AOM, N=3, median age 39

90 months]; and 3) MEF culture negative but NPA culture positive for S. pneumoniae [Pnc

91 carriers with a probable Pnc AOM, N=34, median age 33.5 months].

92 All the 75 pneumococcal isolates were susceptible to penicillin (MIC $\leq 0.06 \mu \mathrm{g} / \mathrm{mL}$ ). One

93 was non-susceptible to erythromycin (MIC $\geq 0.5, \mu \mathrm{g} / \mathrm{mL}$ ) and two to tetracycline (MIC $\geq 4$,

$94 \mu \mathrm{g} / \mathrm{mL})$.

95 Among the 75 isolates, 14 different serotypes were found: $19 \mathrm{~F}(27 \%), 23 \mathrm{~F}(25 \%), 6 \mathrm{~B}, 14$,

96 6A, 19A, 11A, 9V, 18C, 24, 33, 3,15A, and 38, in decreasing order of incidence (Figure

97 1).

98 The serotype, sequence type, and antimicrobial susceptibility results were the same for

99 both MEF and NPA isolates from the same child. Serotypes 9V, 19A, 24, and 33 were

100 found only in the Pnc carriers with Pnc AOM, and serotypes 3, 6A, 15A, 18C and 38 only

101 in the Pnc carriers with probable Pnc AOM.

102 Fifteen of the $75(20 \%)$ isolates were positive for the PI-1 genes $r r g C$ and $r l r A$, and were

103 detected among serotypes 6B (6/7 isolates), 6A (4/5 isolates), $9 \mathrm{~V}$ ( $2 / 2$ isolates), 23F (2/19

104 isolates), and 38 (1/1 isolate). Among the Pnc carriers with Pnc AOM, eight of the 41

105 (20\%) pneumococcal isolates from four children had PI-1 genes; the corresponding

106 number was seven of $34(21 \%)$ among the Pnc carriers with probable Pnc AOM. None of

107 the three children with Pnc AOM and without Pnc carriage (MEF+/NPA-) had

108 pneumococcal isolates carrying PI-1 genes. PI-2 genes were not detected in any of the

109 isolates.

110 Several criteria were used to select isolates for genotyping by MLST: all isolates from

111 Pnc carriers with Pnc AOM (MEF+/NPA+), all pilus positive isolates, and one isolate for 
112 each serotype. In addition, if within a certain serotype (e.g. 6A or 6B) there were both

113 positive and negative pilus islet gene results, one of each was genotyped. The 52 isolates

114 genotyped from 33 children belonged to 30 different STs, the most common being ST37

$115(\mathrm{~N}=4)$ and ST124 ( $\mathrm{N}=4$; Table 1). According to the eBURST V3 program, these STs

116 belonged to 18 known CCs. In addition, two STs were singletons and three had no

117 predicted founder. Most of the strains belonged to CC439 (11/52; 21\%) and CC490 (6/52;

$11812 \%)$. PI-1 was associated with serotypes 6A $(P<0.005), 6 \mathrm{~B}(P=0.0002)$ and $9 \mathrm{~V}(P<0.05)$

119 and with genotype CC490 ( $P=0.0002)$. PI-1 was not associated with the PCV7/PCV10

120 serotypes when compared to the non-PCV7/PCV10 serotypes (PCV7 and PCV10, 10/56;

$12118 \%$ vs. $5 / 19 ; 26 \% ; P=0.51$ ), nor with the PCV13 serotypes (PCV13, $14 / 56 ; 25 \%$ vs.

122 non-PCV13, 1/19; 5\%; $P=0.10)$.

\section{Discussion}

125 This study characterized the molecular background of pneumococcal isolates cultured

126 from children with diagnosed AOM in Finland prior to the era of increased antimicrobial

127 resistance and the use of pneumococcal conjugate vaccine. Thus far, the existence of

128 pneumococcal pilus genes has been studied mainly among invasive isolates, and the

129 prevalence of PI-1 among these isolates has been around 30\% [6, 7]. The prevalence of

130 PI-2 has been shown to be $16 \%$ for both invasive and nasopharyngeal isolates [3]. A

131 recent report from Israel showed that the frequency of PI-1 was the same 30\% and that of

132 PI-2 was 7\% among the MEF isolates [5]. In the U.S.A. the prevalence of PI-1 among

133 nasopharyngeal isolates was shown to decline from $24 \%$ to $15 \%$ following the PCV7

134 introduction; however, it has increased back to pre-PCV7 levels (26\%) in 2007 [9]. In our 
135 study, $20 \%$ of the pneumococcal MEF and/or NPA isolates were positive for PI-1 and 136 none for PI-2.

138 It has been shown that the antimicrobial resistance of $S$. pneumoniae strains causing 139 AOM have increased: recently, the proportion of non-susceptibility to penicillin and 140 macrolides among these isolates has been estimated at between $30 \%$ and $70 \%$ [14]. Our

141 study isolates were collected already in 1990-1992 and all were susceptible to penicillin 142 and almost all to other commonly used antimicrobials. The PI-1 genes were detected 143 among the susceptible AOM isolates, and moreover, more in association with certain 144 serotypes - $6 \mathrm{~A}, 6 \mathrm{~B}$, and $9 \mathrm{~V}$ - than genotypes; this is in contrast to other reports where 145 pilus genes have been associated with a genotype rather than a serotype [5-9]. A recent 146 Israeli study of AOM isolates showed a correlation between PI-1 and antimicrobial 147 resistance, which has also been demonstrated in other previous reports [5-7]. The PMEN 148 clone Spain 9V-3 with ST156 is typically piliated and antimicrobial resistant $[6,12,13]$.

149 Interestingly, we found two piliated and antimicrobial sensitive strains that were clonally 150 related to ST156 (ST162, SLV of ST156), belonging to the same CC156. The 151 antimicrobial sensitivity of these strains and the lower prevalence of PI-1 in our study 152 compared to other studies could be due to the period in which our isolates were collected. 153 Overall pneumococcal antimicrobial resistance was then very low in Finland [10, 13].

155 We did not find any PI-2 positive isolates, nor any such CCs that have been reported as 156 PI-2 positive $[3,5,15]$. This may be due to a small number of isolates and the time period 157 when the isolates were collected. This again is somewhat supportive of the hypothesis of 
158 the pilus being associated with the spread of antimicrobial resistant clones. A recent study

159 showed that in 1999 only 3.6\% of invasive isolates contained PI-2, and in 2006 the

160 prevalence rose to $21 \%[3,5,15]$.

161

162 The MLST results in this study showed great heterogeneity among the MEF and NPA

163 isolates in different children. Most of the PI-1 positive isolates belonged to serotypes and

164 CCs already reported to carry the PI-1 genes, with the exception of CC393, CC439, and

165 CC522, which have not been associated with PI-1 previously $[5,7,8]$. The pneumococcal

166 serotypes detected were the common ones known to cause AOM infections among

167 children [1]. PCV7 and PCV10 would have covered 75\% of the serotypes detected, and

168 PCV13 would have covered $86 \%$. The presence of PI-1 was not associated with the

169 vaccine serotypes, again contrary to earlier reports [6, 8]. However, our finding of a PI-1

170 association with both $6 \mathrm{~A}$ and $6 \mathrm{~B}$ is of special interest. Although the Finnish clinical

171 AOM trial with PCV7 gives reason to expect cross-protection within serogroup 6 [1], the

172 serotypes 6A and 19A, both included only in the PCV13, are of worldwide concern. They

173 cause both invasive and non-invasive disease and have been claimed as replacement

174 serotypes with increasing resistance to antimicrobials $[2,13,14]$. Thus, it will be

175 interesting to study further the changes of AOM isolates in Finland since the early 1990s,

176 following increased use of antimicrobials, and, moreover, the forthcoming large-scale use

177 of a conjugate vaccine that began in September 2010.

178

179 In conclusion, we found that pneumococcal AOM isolates from 1990-1992 carried PI-1

180 genes in rather low prevalence, and PI-2 genes were not found at all in the time prior to 
181 pneumococcal conjugate vaccine and increased antimicrobial resistance. In addition, PI-1

182 was associated with serotype rather than genotype. Based on our results, the significance

183 of the pilus protein encoding islet as a virulence factor in AOM or its association to the

184 spread of antimicrobial resistance remains unsolved. However, including the pilus

185 determinants into the protein vaccines currently under development seems worthwhile.

186

187 Acknowledgement

188 This work was financially supported by the Finnish Ministry of Social Affairs and Health

189 and the Finnish Cultural Foundation. We thank Aila Soininen for her skilled technical

190 assistance.

191

192 Conflict of interest

193 The authors declare that they have no conflict of interest.

194 
196 1. Eskola J, Kilpi T, Palmu A, Jokinen J, Haapakoski J, Herva E, Takala A, Käyhty H,

197 Karma P, Kohberger R, Siber G, Mäkelä PH (2001) Efficacy of a pneumococcal

198 conjugate vaccine against acute otitis media. N Engl J Med 344 (6):403-409.

199 2. Casey JR, Adlowitz DG, Pichichero ME (2010) New patterns in the otopathogens

200 causing acute otitis media six to eight years after introduction of pneumococcal conjugate

201 vaccine. Pediatr Infect Dis J 29 (4):304-309. doi: 10.1097/INF.0b013e3181c1bc48

202 3. Bagnoli F, Moschioni M, Donati C, Dimitrovska V, Ferlenghi I, Facciotti C, Muzzi A,

203 Giusti F, Emolo C, Sinisi A, Hilleringmann M, Pansegrau W, Censini S, Rappuoli R,

204 Covacci A, Masignani V, Barocchi MA (2008) A second pilus type in Streptococcus

205 pneumoniae is prevalent in emerging serotypes and mediates adhesion to host cells. J

206 Bacteriol 190 (15):5480-5492. doi: 10.1128/JB.00384-08

207 4. Barocchi MA, Ries J, Zogaj X, Hemsley C, Albiger B, Kanth A, Dahlberg S, Fernebro

208 J, Moschioni M, Masignani V, Hultenby K, Taddei AR, Beiter K, Wartha F, von Euler A,

209 Covacci A, Holden DW, Normark S, Rappuoli R, Henriques-Normark B (2006) A

210 pneumococcal pilus influences virulence and host inflammatory responses. Proc Natl

211 Acad Sci U S A 103 (8):2857-2862. doi: 10.1073/pnas.0511017103

212 5. Moschioni M, De Angelis G, Melchiorre S, Masignani V, Leibovitz E, Barocchi MA,

213 Dagan R (2009) Prevalence of pilus encoding islets among acute otitis media

214 Streptococcus pneumoniae isolates from Israel. Clin Microbiol Infectdoi: 10.1111/j.1469-

$215 \quad 0691.2009 .03105 . x$ 
216 6. Aguiar SI, Serrano I, Pinto FR, Melo-Cristino J, Ramirez M (2008) The presence of

217 the pilus locus is a clonal property among pneumococcal invasive isolates. BMC

218 Microbiol 8:41. doi: 10.1186/1471-2180-8-41

219 7. Moschioni M, Donati C, Muzzi A, Masignani V, Censini S, Hanage WP, Bishop CJ,

220 Reis JN, Normark S, Henriques-Normark B, Covacci A, Rappuoli R, Barocchi MA (2008)

221 Streptococcus pneumoniae contains 3 rlrA pilus variants that are clonally related. J Infect

222 Dis 197 (6):888-896. doi: $10.1086 / 528375$

223 8. Basset A, Trzcinski K, Hermos C, O'Brien KL, Reid R, Santosham M, McAdam AJ,

224 Lipsitch M, Malley R (2007) Association of the pneumococcal pilus with certain capsular

225 serotypes but not with increased virulence. J Clin Microbiol 45 (6):1684-1689. doi:

226 10.1128/JCM.00265-07

227 9. Regev-Yochay G, Hanage WP, Trzcinski K, Rifas-Shiman SL, Lee G, Bessolo A, 228 Huang SS, Pelton SI, McAdam AJ, Finkelstein JA, Lipsitch M, Malley R (2010) Re-

229 emergence of the type 1 pilus among Streptococcus pneumoniae isolates in

230 Massachusetts, USA. Vaccine 28 (30):4842-4846. doi: 10.1016/j.vaccine.2010.04.042

231 10. Manninen R, Huovinen P, Nissinen A (1997) Increasing antimicrobial resistance in

232 Streptococcus pneumoniae, Haemophilus influenzae and Moraxella catarrhalis in

233 Finland. J Antimicrob Chemother 40 (3):387-392.

234 11. Virolainen A, Salo P, Jero J, Karma P, Eskola J, Leinonen M (1994) Comparison of

235 PCR assay with bacterial culture for detecting Streptococcus pneumoniae in middle ear

236 fluid of children with acute otitis media. J Clin Microbiol 32 (11):2667-2670.

237 12. Sjöström K, Blomberg C, Fernebro J, Dagerhamn J, Morfeldt E, Barocchi MA, 238 Browall S, Moschioni M, Andersson M, Henriques F, Albiger B, Rappuoli R, Normark S, 
239 Henriques-Normark B (2007) Clonal success of piliated penicillin nonsusceptible 240 pneumococci. Proc Natl Acad Sci U S A 104 (31):12907-12912. doi: $241 \quad 10.1073 /$ pnas.0705589104

242 13. Siira L, Rantala M, Jalava J, Hakanen AJ, Huovinen P, Kaijalainen T, Lyytikäinen O, 243 Virolainen A (2009) Temporal trends of antimicrobial resistance and clonality of invasive 244 Streptococcus pneumoniae isolates in Finland, 2002 to 2006. Antimicrob Agents 245 Chemother 53 (5):2066-2073. doi: 10.1128/AAC.01464-08

246 14. Leibovitz E, Broides A, Greenberg D, Newman N (2010) Current management of 247 pediatric acute otitis media. Expert Rev Anti Infect Ther 8 (2):151-161. doi: $248 \quad 10.1586 /$ eri.09.112

249 15. Zähner D, Gudlavalleti A, Stephens DS (2010) Increase in pilus islet 2-encoded pili 250 among Streptococcus pneumoniae isolates, Atlanta, Georgia, USA. Emerg Infect Dis 16 251 (6):955-962. doi:10.3201/eid1606.091820

252

253

254 


\section{Figure caption}

256 Fig 1 Serotype distribution of the 75 study isolates and $r l r A$ islet frequency among the 257 serotypes 
Table 1. $r l r A$ islet, serotypes, multi locus sequence typing (MLST) clonal complexes

260 (CCs), and sequence type (ST) results for the 52 pneumococcal isolates from 33 children.

\begin{tabular}{|c|c|c|c|c|c|c|}
\hline $\begin{array}{l}\text { rlrA } \\
\text { islet }\end{array}$ & $\begin{array}{l}\text { Serotype } \\
\text { of the } \\
\text { child }\end{array}$ & $\begin{array}{l}\text { Site of } \\
\text { isolation }\end{array}$ & $\underline{\mathrm{CC}^{\mathrm{C}}}$ & $\underline{\mathbf{S T}^{\mathrm{d}}}$ & Allelic profile ${ }^{d, e}$ & $\begin{array}{l}\text { Age } \\
\text { (mo) }\end{array}$ \\
\hline \pm & $6 \mathrm{~A}$ & MEF-/NPA+ & $\underline{490}$ & $\underline{488}$ & 2-13-9-1-6-28-14 & $\underline{32}$ \\
\hline \pm & $\underline{6 \mathrm{~A}}$ & MEF-/NPA+ & $\underline{490}$ & $\underline{490}$ & 2-13-9-1-6-19-14 & $\underline{32}$ \\
\hline \pm & $\underline{6 \mathrm{~A}}$ & $\underline{\mathrm{MEF}-/ \mathrm{NPA}+}$ & $\underline{490}$ & $\underline{490}$ & 2-13-9-1-6-19-14 & $\underline{50}$ \\
\hline \pm & $\underline{6 \mathrm{~A}}$ & $\underline{\mathrm{MEF}-/ \mathrm{NPA}+}$ & $\underline{490}$ & $\underline{518}$ & $\underline{2-45-9-1-6-19-14}$ & $\underline{36}$ \\
\hline \pm & $\underline{6 B}$ & $\underline{\mathrm{MEF}+/ \mathrm{NPA}+}$ & $\underline{490}$ & $\underline{208}$ & $\underline{10-13-2-1-6-19-14}$ & $\underline{41}$ \\
\hline \pm & $\underline{6 B}$ & $\underline{M E F+/ N P A+}$ & $\underline{522}$ & $\underline{522}$ & $\underline{18-12-9-1-6-31-6}$ & $\underline{13}$ \\
\hline \pm & $\underline{6 B}$ & MEF-/NPA+ & $\underline{138}$ & $\underline{138}$ & $\underline{7-5-8-5-10-6-14}$ & $\underline{50}$ \\
\hline \pm & $\underline{6 B}$ & $\underline{\mathrm{MEF}-/ \mathrm{NPA}+}$ & $\underline{138}$ & $\underline{4594}$ & 7-13-8-6-10-4-1 & $\underline{9}$ \\
\hline \pm & $\underline{9 \mathrm{~V}}$ & $\underline{\mathrm{MEF}+/ \mathrm{NPA}+}$ & $\underline{156}$ & $\underline{162}$ & $\underline{7-11-10-1-6-8-14}$ & $\underline{52}$ \\
\hline \pm & $\underline{23 F}$ & $\underline{\mathrm{MEF}+/ \mathrm{NPA}+}$ & $\underline{439}$ & $\underline{515}$ & $\underline{16-8-9-1-6-4-72}$ & $\underline{33}$ \\
\hline \pm & $\underline{38}$ & $\underline{\text { MEF-/NPA }{ }^{a}}$ & $\underline{393}$ & $\underline{310}$ & $\underline{1-43-41-18-13-49-6}$ & 42 \\
\hline$=$ & $\underline{3}$ & $\underline{\mathrm{MEF}-/ \mathrm{NPA}+}$ & $\underline{180}$ & $\underline{180}$ & $7-15-2-10-6-1-22$ & $\underline{23}$ \\
\hline$=$ & $\underline{6 \mathrm{~A}}$ & $\underline{\mathrm{MEF}-/ \mathrm{NPA}+}$ & $\underline{460}$ & $\underline{460}$ & $\underline{5-7-4-10-10-1-27}$ & $\underline{21}$ \\
\hline$=$ & $\underline{6 \mathrm{~A}}$ & $\underline{\mathrm{MEF}-/ \mathrm{NPA}+}$ & $\underline{100}$ & $\underline{100}$ & $\underline{5-12-29-12-9-39-18}$ & $\underline{13}$ \\
\hline$=$ & $\underline{6 B}$ & $\underline{M E F+/ N P A-}$ & NPF & $\underline{1752}$ & $\underline{7-61-1-1-17-1-192}$ & $\underline{11}$ \\
\hline$=$ & $\underline{11 \mathrm{~A}}$ & $\underline{\mathrm{MEF}+\mathrm{NPA}-}$ & $\underline{62}$ & $\underline{500}$ & $\underline{10-5-29-12-16-3-14}$ & $\underline{41}$ \\
\hline$=$ & 14 & $\underline{\mathrm{MEF}+/ \mathrm{NPA}+}$ & $\underline{124}$ & $\underline{124}$ & 7-5-1-8-14-11-14 & $\underline{72}$ \\
\hline$=$ & $\underline{14}$ & $\underline{\mathrm{MEF}+/ \mathrm{NPA}+}$ & $\underline{124}$ & $\underline{124}$ & 7-5-1-8-14-11-14 & $\underline{28}$ \\
\hline
\end{tabular}




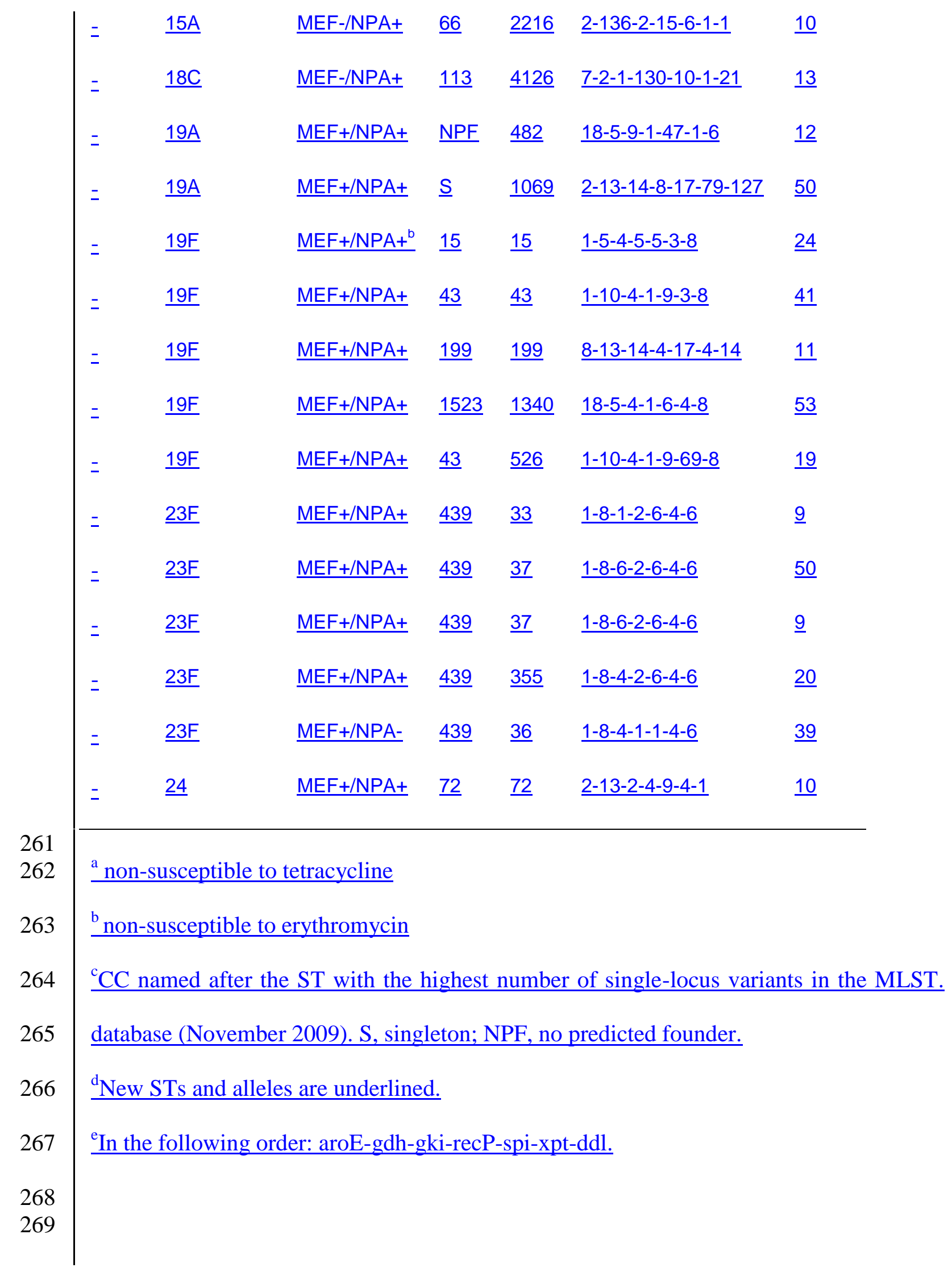




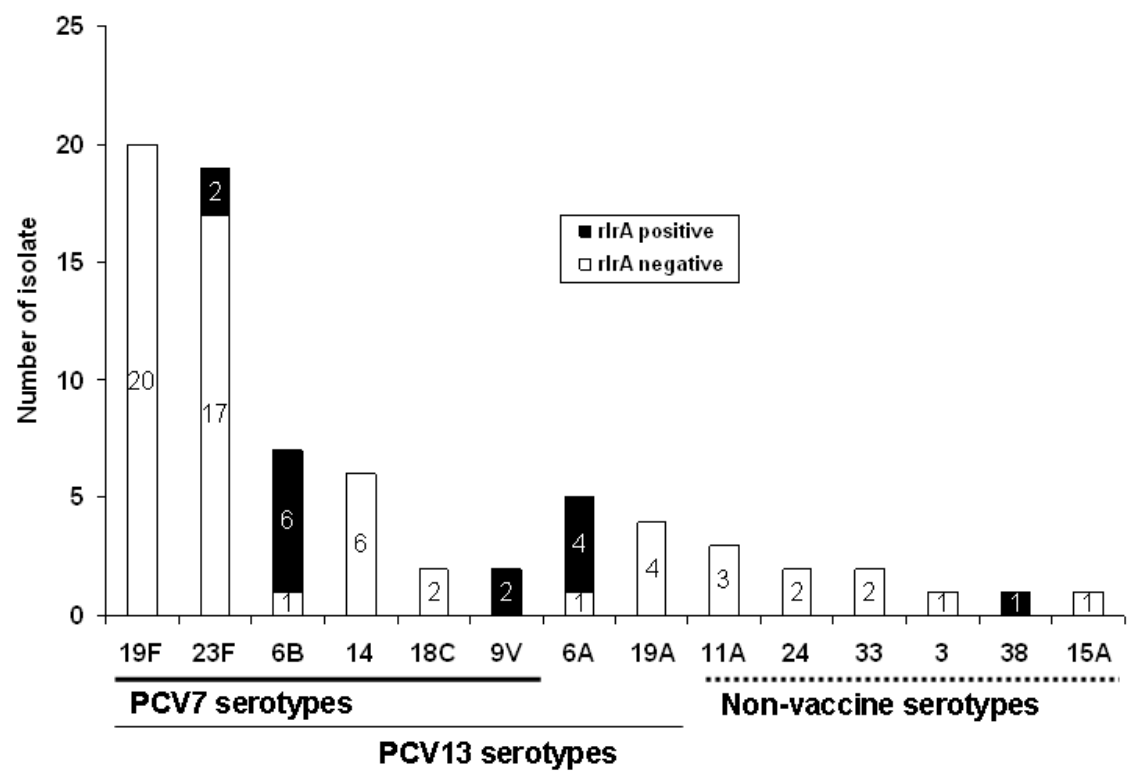

